\title{
Modeling Effect of Bitumen Extraction Processes on Oil
} Sands Tailings Ponds

\author{
Silawat Jeeravipoolvarn ${ }^{1}$, Warren Miller ${ }^{2}$, Don Scott ${ }^{3}$, Louis Kabwe ${ }^{3}$ and Ward Wilson ${ }^{3}$ \\ 1. FSCA Software, Khon Kaen 40000, Thailand \\ 2. Advisian, Worley Parsons Group, Perth, Western Australia 6000, Australia \\ 3. Department of Civil and Environmental Engineering, University of Alberta, Edmonton, Alberta T6G 1H9, Canada
}

\begin{abstract}
In the oil sands industry, high temperature with the addition of a caustic dispersing agent has formed the basis of the Clark hot water extraction process used successfully on a commercial scale to recover bitumen from surface mined oil sands ore since 1967. Processes different from the established Clark process (high temperature and caustic) have been developed to work at a range of temperatures with or without the use of sodium hydroxide. Large scale bitumen extraction pilot tests were performed with two different extraction processes and large strain consolidation tests were performed on the resulting different tailings. These consolidation tests determined the compressibility and hydraulic conductivity relationships with void ratio which are engineering properties that influence the long-term disposal of the fine tailings. They were used in large strain consolidation numerical analyses of storage ponds to predict water release rates and changes to surface elevations that impact storage volumes and elevation of reclamation surfaces.
\end{abstract}

Key words: Oil sands, tailings, consolidation, seepage.

\section{Introduction}

In the oil sands industry, high temperature and addition of caustic $(\mathrm{NaOH})$ form the basis of the caustic process used successfully to recover bitumen from surface mined oil sands ore. However, the caustic process results in the creation of extremely dispersed, high void ratio fine tailings composed primarily of silt, clay, water and residual bitumen. These caustic-affected fine tailings exhibit extremely low consolidation rates and shear strengths and require considerable real estate for surface storage. Non-caustic processes have been developed to improve bitumen recovery, improve the process water chemistry and reduce the dispersion of fines during bitumen extraction. Producing tailings with reduced fines dispersion should improve the consolidation and strength properties of the fine tailings. A potential reduction in fine tailings volume and improved

\footnotetext{
Corresponding author: Silawat Jeeravipoolvarn, Ph.D., research fields: geotechnical engineering. E-mail: Silawat@gmail.com.
}

geo-environmental behavior provided an environmental and economic incentive to examine the relative differences between the characteristics of the fine tailings derived from a caustic and a non-caustic extraction process. Large strain consolidation tests were performed on both caustic and non-caustic fine tailings to determine the void ratio-effective stress and hydraulic conductivity-void ratio relationships. These relationships are used in large strain consolidation analyses of a storage pond to predict water release rates and changes to surface elevations that impact storage volumes and elevation of reclamation surfaces. The analyses were first used to model long-term $1 \mathrm{~m}$ high standpipe tests on both materials to verify the large strain consolidation test results and the analysis equations used in modelling. They were then used in consolidation analyses of commercial scale tailings ponds to examine the benefit of non-caustic tailings in long term tailings disposal.

\section{Oil Sands and Extraction Methods}

Fine tailings were generated from 80 tonne samples 
of typical Suncor Energy Inc. ore that was processed using both a caustic and a non-caustic extraction method. The extraction process water was determined based on the water source that would be used for commercial operation. Recycled pond water from Syncrude's Mildred Lake tailings pond was used for the caustic process. Sodium hydroxide was added to aid extraction: $0.005 \mathrm{wt} \%$. The non-caustic process utilized Athabasca river water which was treated with sulfuric acid and lime to remove bicarbonate and increase calcium content in the water. The river water (initial $\mathrm{pH}$ of 7.4 ) was treated by adding a $10 \%$ sulfuric acid solution to bring the $\mathrm{pH}$ to 5.0 , and subsequently adding a $4 \%$ (by weight) lime slurry to increase the $\mathrm{pH}$ back to 7.4 , resulting in $40 \mathrm{ppm}$ of $\mathrm{Ca}^{2+}$ in solution. This chemical treatment was proposed to improve the settling behavior of the non-caustic fine tailings [1].

\section{Characteristics of the Tailings}

\subsection{PSD (Particle Size Distribution)}

The fine material (less than $45 \mu \mathrm{m}$ ) in the fine tailings originates from inter-bedded clay bands in the oil sands formations. The extent that these clay bands are broken up depends on the mining methods, the bitumen extraction processes, and the composition of the oil sands ore. Non-dispersed and dispersed hydrometer tests were performed to determine particle size distributions and the degree of fines dispersion for both the caustic and the non-caustic fine tailings. The hydrometer tests followed the procedure outlined in ASTM D 4221-99R05 [2] for determining the dispersive characteristics of clay soil by double hydrometer in conjunction with the ASTM D 0422-63R07 procedure for the standard particle size analysis of soils [3]. The double hydrometer method compares the clay sized fraction of a standard hydrometer test with a second hydrometer test that involves no mechanical agitation or addition of dispersing agent.

The PSDs of the caustic fine tailings are shown in Fig. 1. There is no difference between the dispersed and the non-dispersed tests as the caustic extraction procedure fully disperses the ore. The PSDs of the non-caustic fine tailings are shown in Fig. 2. The particle size distributions of these non-caustic fine tailings are indicative of a much less dispersed material. The non-dispersed and dispersed distributions of non-caustic fine tailings were generally similar for material coarser than approximately $4 \mu \mathrm{m}$, after which, the non-dispersed test had substantially less finer material. The divergence of the distributions resulted in a percent dispersion of only $10 \%$ (clay sized fractions of $5 \%$ and $48 \%$ for the non-dispersed and dispersed tests, respectively). Thus, the non-caustic fine tailings contain fine sized material that exists as small silt and clay size lumps of clay band that were not dispersed during the extraction process. The non-dispersed tests correctly show the PSDs of the tailings materials.

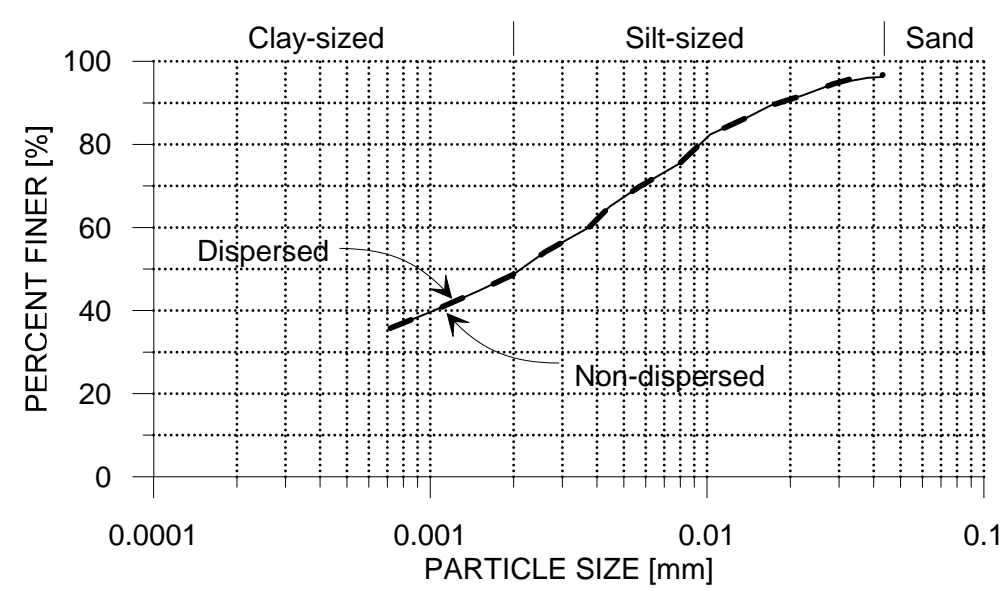

Fig. 1 PSD of caustic oil sands tailings. 


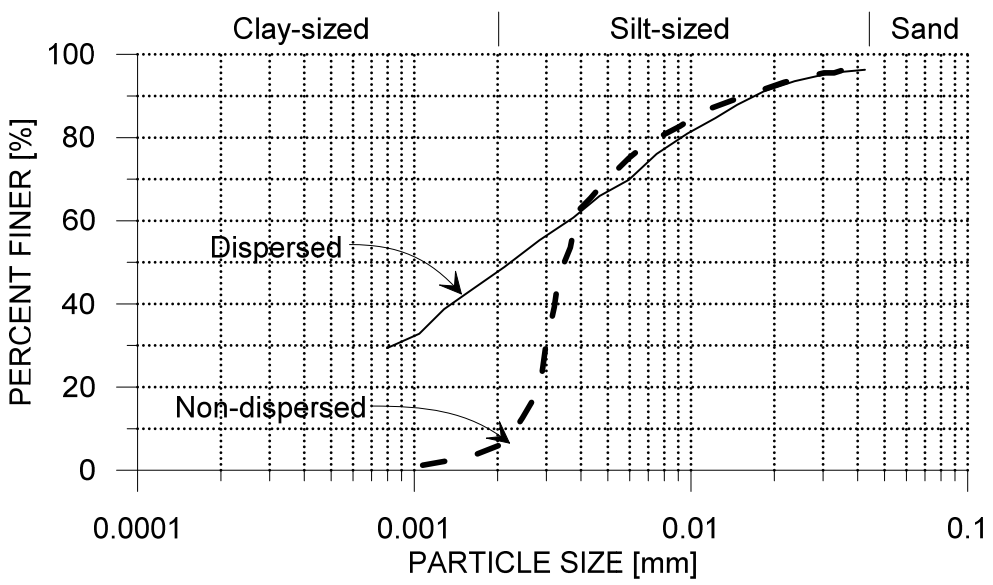

Fig. 2 PSD of non-caustic oil sands tailings.

Table 1 Index properties of fine tailings [5].

\begin{tabular}{lllllllll}
\hline \multirow{2}{*}{ Fine tailings type $\begin{array}{l}\text { Solids } \\
\text { content }(\%)\end{array}$} & $\begin{array}{l}\text { Fines content Bitumen content } \\
(\%)\end{array}$ & $\begin{array}{l}\text { Water } \\
\text { by dry mass (\%) } \\
\text { content (\%) }\end{array}$ & $\begin{array}{l}\text { Specific } \\
\text { gravity }\end{array}$ & $\begin{array}{l}\text { Liquid limit } \\
(\%)\end{array}$ & $\begin{array}{l}\text { Plastic limit } \\
(\%)\end{array}$ & $\begin{array}{l}\text { Plasticity index } \\
(\%)\end{array}$ \\
\hline Caustic & 8.5 & 99 & 5.9 & 1,076 & 2.48 & 52.1 & 26.9 & 25.2 \\
Non-caustic & 7.5 & 99 & 6.7 & 1,233 & 2.45 & 58.3 & 28.2 & 30.1 \\
\hline
\end{tabular}

Table 2 Minerals in clay-sized fraction of fine tailings [5].

\begin{tabular}{llllll}
\hline Fine tailings type & Quartz (\%) & Kaolinite (\%) & Illite (\%) & Mixed (\%) & Smectite (\%) \\
\hline Caustic & 2 & 76 & 18 & 4 & 0 \\
Non-caustic & 2 & 75 & 19 & 4 & 0 \\
\hline
\end{tabular}

\subsection{Index Properties}

The index properties of both tailings are shown in Table 1. From an engineering perspective, the differences between the liquid limits and plasticity indices for the two fine tailings are minor. Based on these results, the deposits would tend to have about the same engineering behavior once water contents approaching typical geotechnical ranges were achieved. Currently, the water contents of the fine tailings are much greater than the liquid limit and the fine tailings exist as slurries.

\subsection{Clay Sized Minerals}

The mineralogy of the clay sized (less than $2 \mu \mathrm{m}$ ) fraction of both tailings is shown in Table 2. The mineralogy of fine tailings is not affected by the type of extraction process or the process water. It is a reflection of the mineralogy of the oil sands ore used to generate the fine tailings. This is supported by the consistency between the two fine tailings materials. The caustic hot water extraction process does not alter the clay mineralogy in the fine tailings [4]. Thus, mineralogy should not play a significant role when fine tailings from the same ore are compared for geotechnical engineering behavior.

\section{Consolidation Behavior}

The infinitesimal consolidation theory (Terzaghi consolidation theory) is not suitable for soft soils that undergo large amounts of volume change. A finite strain consolidation theory [6] has been widely used for oil sands fine tailings $[7,8]$. The finite strain consolidation theory requires compressibility and hydraulic conductivity relationships to be obtained from a large strain consolidation test. Infinitesimal theory does not correctly calculate the hydraulic conductivity from consolidation-time measurements and hydraulic conductivity needs to be measured directly due to the large volume changes that take place in soft soils. Thus, standard consolidation tests cannot be used for this purpose. Instead, a large strain 
consolidation testing apparatus (slurry consolidometer) was used to determine the consolidation characteristics of the fine tailings. Large strain slurry consolidometer tests provide compressibility (void ratio-effective stress relationship) and hydraulic conductivity (hydraulic conductivity-void ratio) relationships. Both relationships are required to define the material relationships to be used in large strain consolidation numerical modeling of tailings ponds.

The compressibilities of both tailings are shown in Fig. 3. Despite the coarser grain sizes of the non-caustic tailings, the compressibilities are similar except at high confining stresses where the non-caustic material is more compressible. The compressibility relationships used in the numerical analyses are shown in the figure.

The hydraulic conductivities of both tailings are shown in Fig. 4 with the relationships used in the numerical analyses. As would be expected, the coarser grain sized non-caustic tailings are about five times more permeable than the caustic tailings. All hydraulic conductivities, however, are low indicating that consolidation in tailings ponds will be slow.

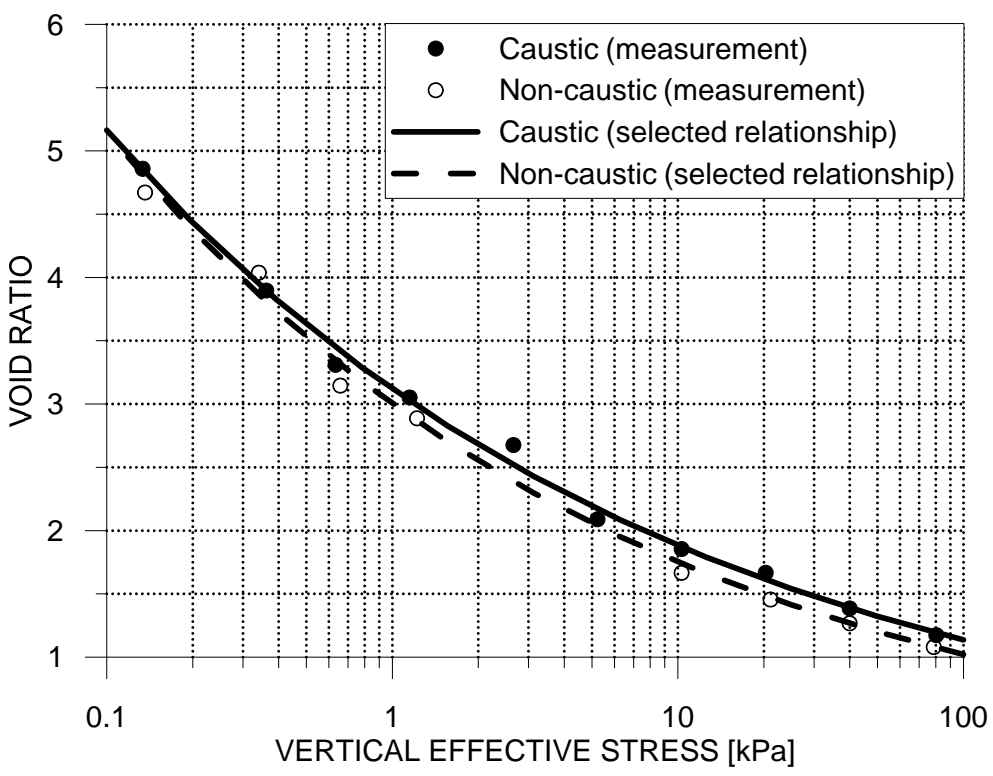

Fig. 3 Compressibilities for caustic and non-caustic oil sands tailings [1].

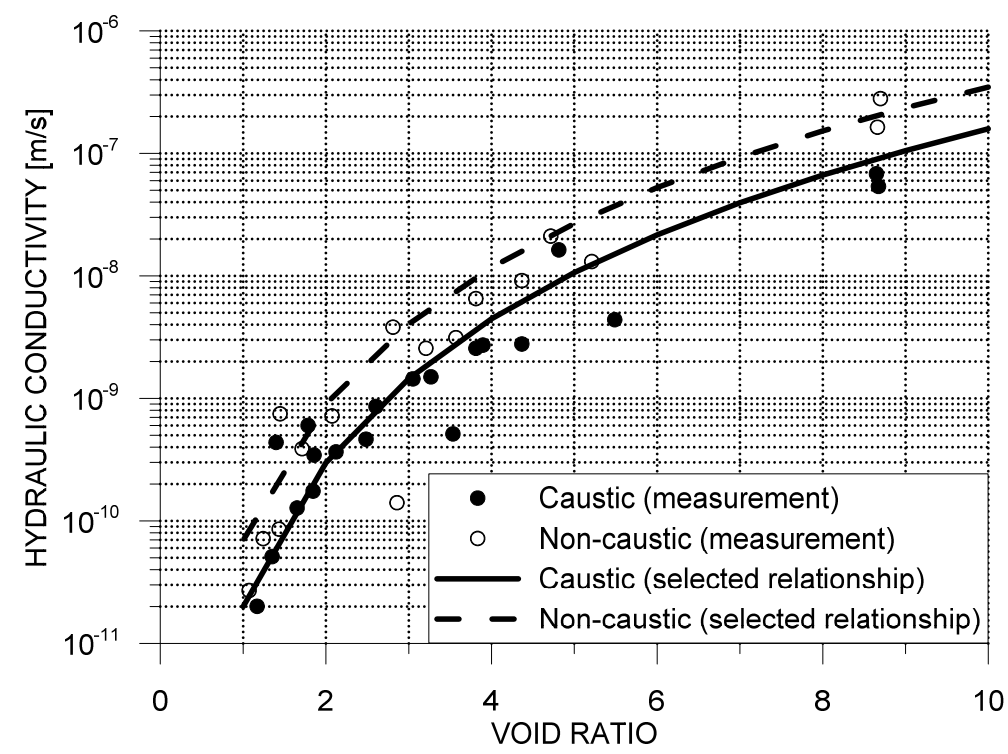

Fig. 4 Hydraulic conductivities for caustic and non-caustic oil sands tailings [1]. 


\section{Standpipe Tests}

Self-weight consolidation tests were performed using standpipe columns $1 \mathrm{~m}$ in height. The experimental setup for the $1 \mathrm{~m}$ standpipes is shown in Fig. 5. The inside diameter was $9.5 \mathrm{~cm}$ and wall thickness was $0.28 \mathrm{~cm}$. The $1 \mathrm{~m}$ standpipes were designed for single drainage (upward only) and manometers were positioned within the fine tailings sample in the form of glass tubing. The base of the standpipe was sealed and only upwards drainage was allowed to occur during the test. This would simulate an impervious layer beneath the fine tailings in a tailings pond.

The tests ran for almost two years for the caustic tailings and even then full consolidation was not achieved. Stress and pressure profiles at four times are shown in Fig. 6. Adjusted total stress and excess pore pressures are shown [9]. The much slower pore pressure dissipation of the caustic tailings is apparent at all time intervals. Both tailings consolidated to a height of about $0.6 \mathrm{~m}$ and if the caustic tailings would have been allowed to fully consolidate, the total settlement for the two materials would have been similar. This result reinforces the similar compressibility relationships found in the large strain consolidation tests. The percent consolidation with time is shown in Fig. 7. The non-caustic tailings were almost fully consolidated after 446 days while the caustic tailings

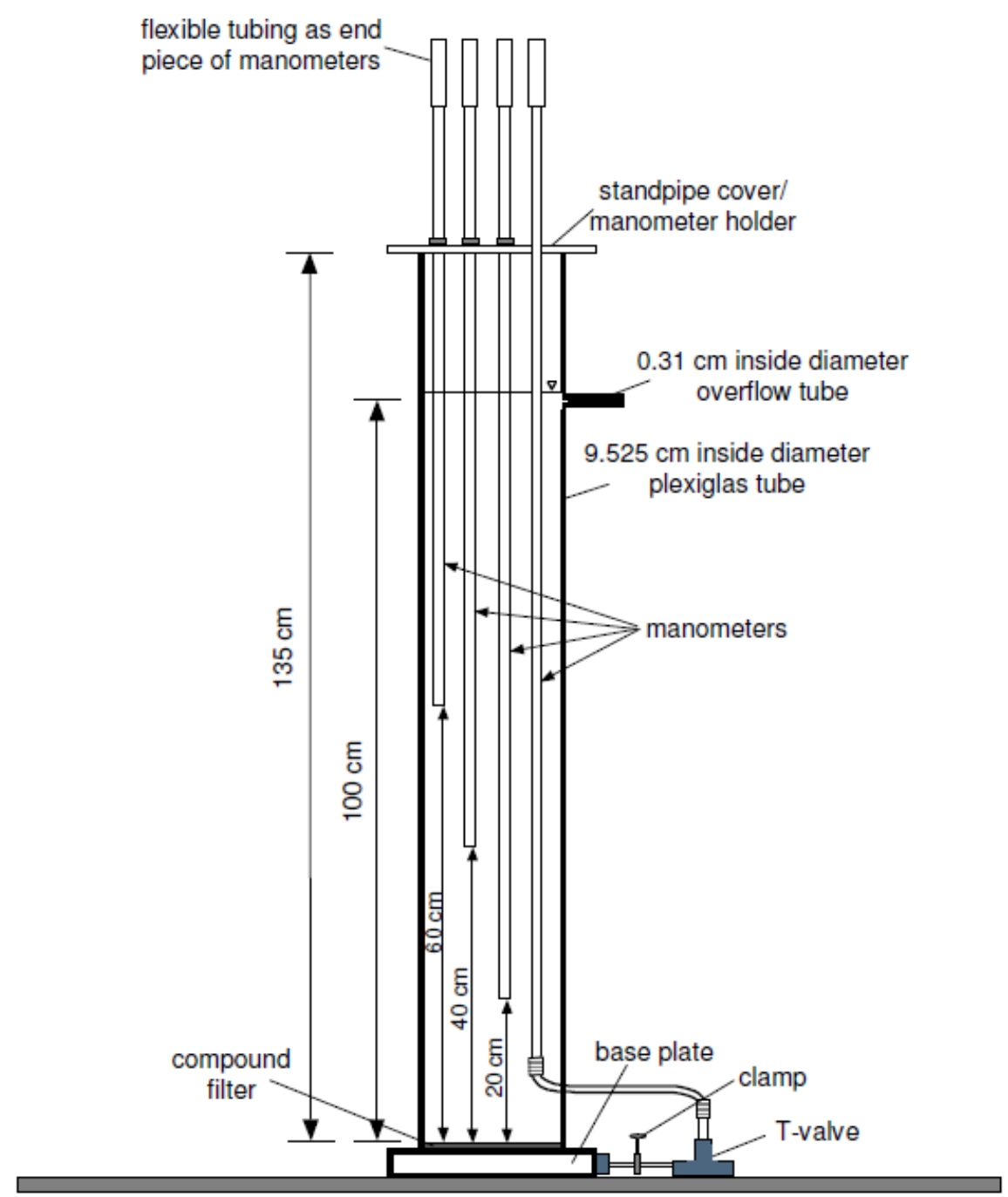

Fig. 5 The $1 \mathrm{~m}$ standpipe test [5]. 


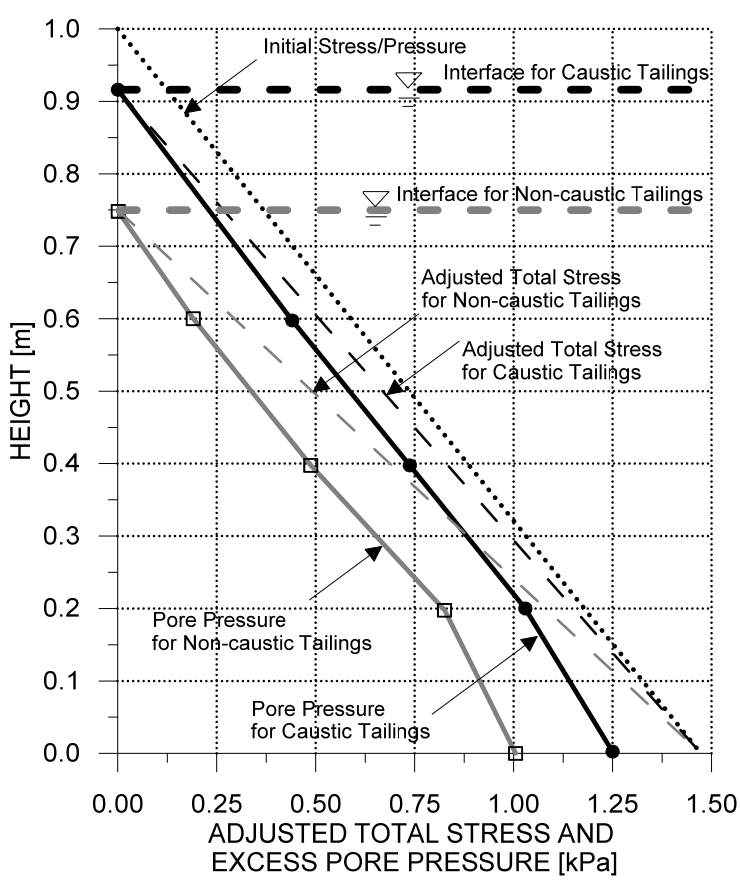

(a)

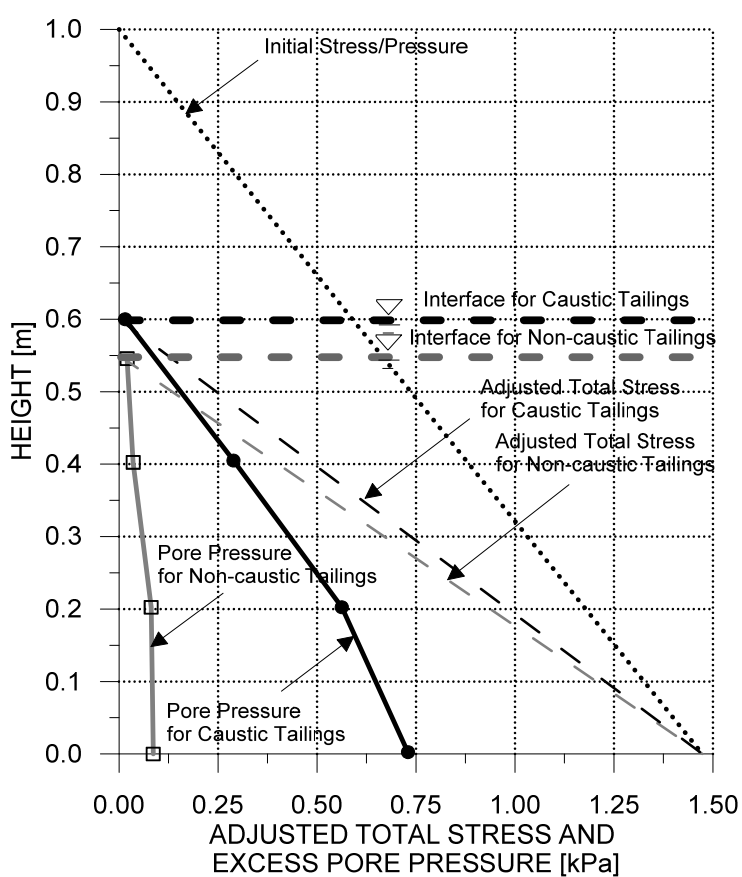

(c)

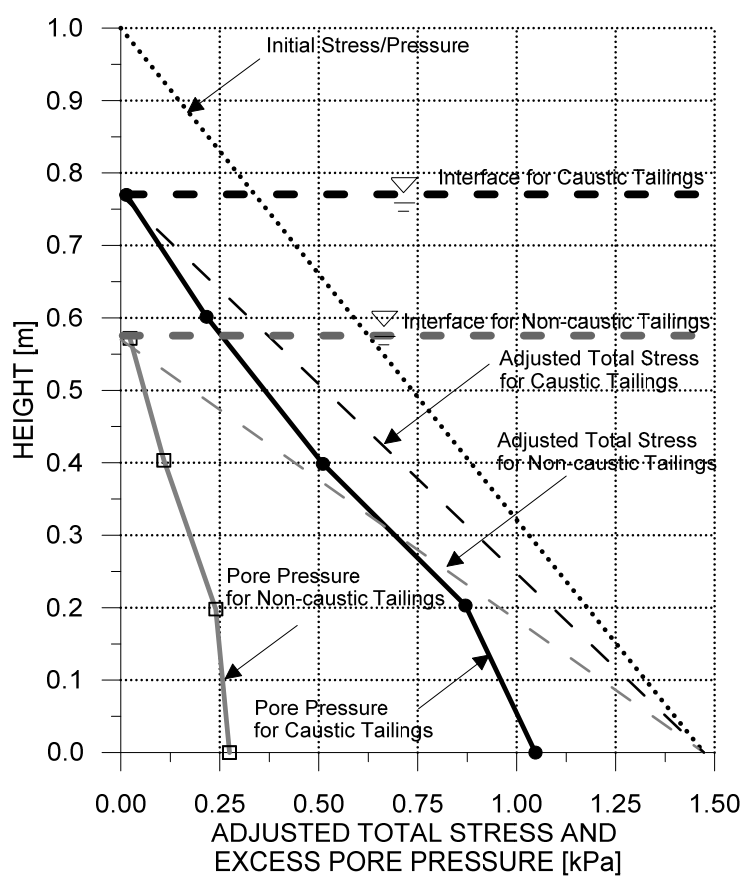

(b)

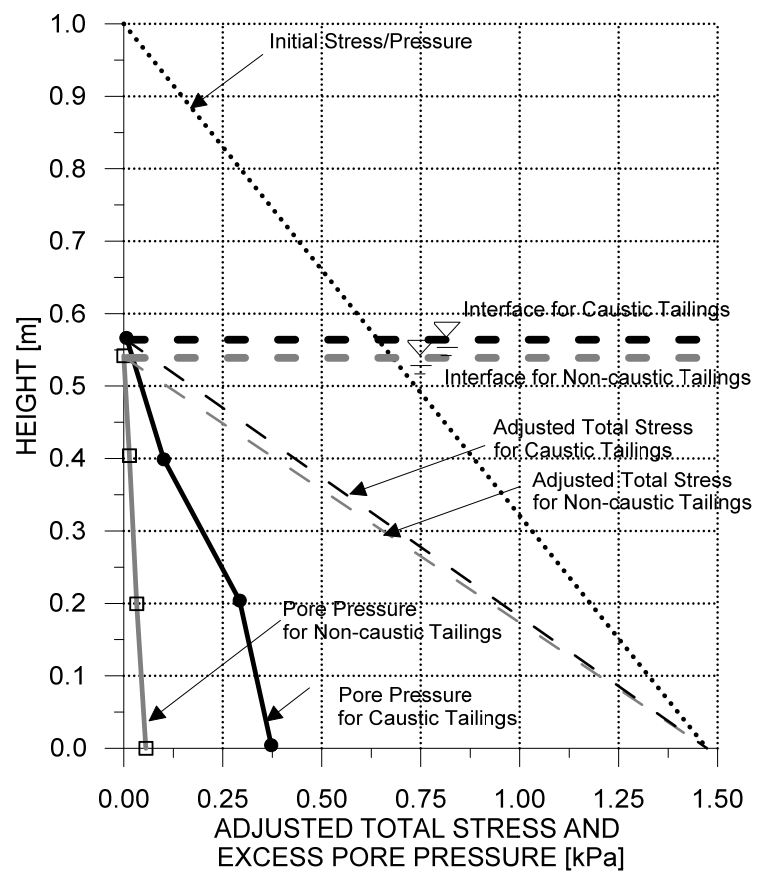

(d)

Fig. 6 Stress and pressure profiles in standpipes: (a) 50 days; (b) 200 days; (c) 400 days; (d) 446 days (non-caustic), 641 days (caustic).

were only about $70 \%$ consolidated after 641 days. The solids contents with depth at the end of the tests for both tailings are shown in Fig. 8. The initial solids contents were about $20 \%$ so both tailings had increased in solids contents to somewhat similar values. The major difference between the two self-weight consolidation standpipe tests was in the rate of consolidation which is a reflection of the difference in 


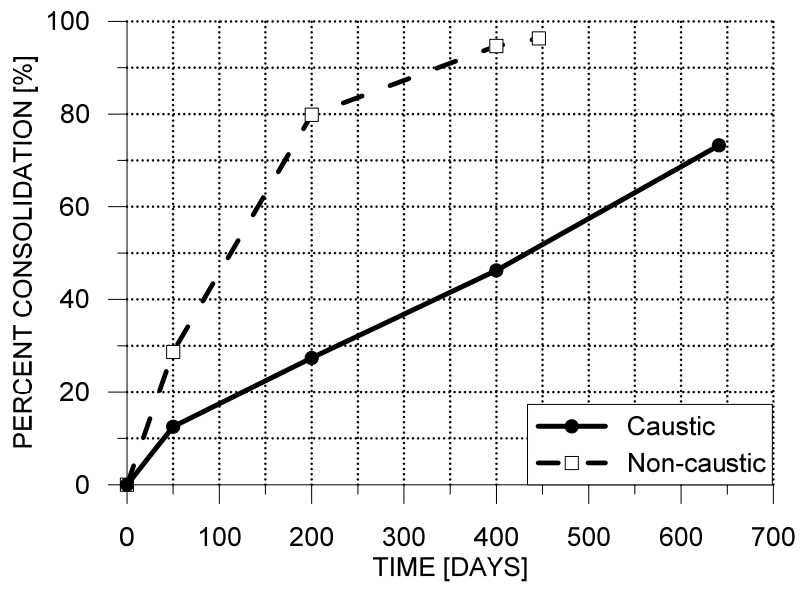

Fig. 7 Rate of self-weight consolidation.

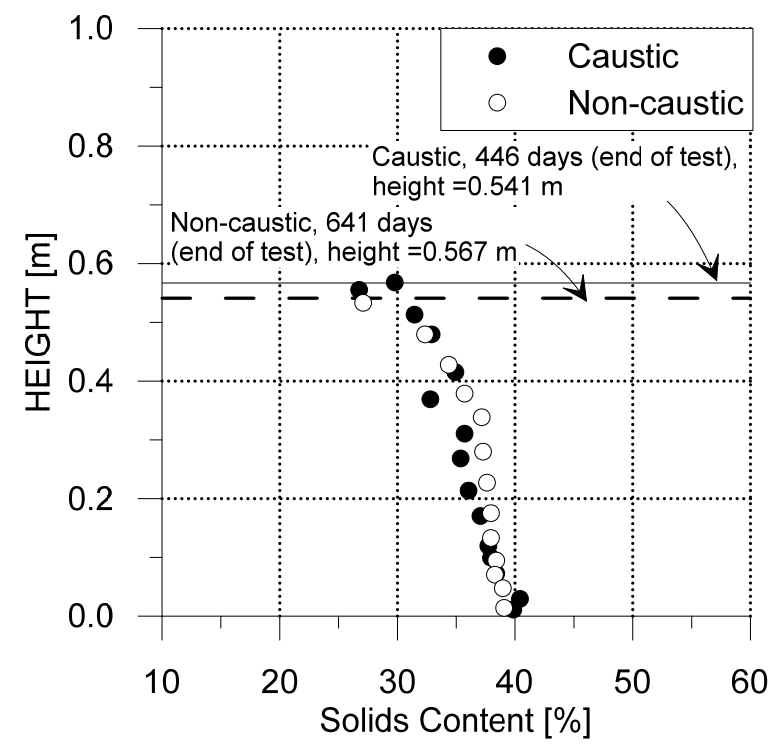

Fig. 8 Solids content profiles at the end of the tests.

hydraulic conductivity.

These standpipe test results will be modeled to validate both the large strain consolidation test results and the numerical model used in the analyses.

\section{Finite Strain Consolidation Model}

The non-linear finite strain consolidation theory was developed by Gibson, England and Hussey in 1967 [6]. The theory unlocks the limitation of small strains, and allows non-linear soil compressibility and hydraulic conductivity to be utilized. The theory is used to simulate consolidation behavior of soft soils and slurries where strains of unrestricted magnitude are contemplated.
The governing equation of the finite strain consolidation theory in terms of excess pore water pressure [10] is expressed as Eq. (1):

$$
\frac{\partial}{\partial z}\left[\frac{-k}{\gamma_{w}(1+e)} \frac{\partial u}{\partial z}\right]+\frac{\partial e}{\partial \sigma^{\prime}}\left[(G s-1) \gamma_{w} \frac{\partial \Delta z}{\partial t}-\frac{\partial u}{\partial t}\right]=0
$$

where, $k$ is the hydraulic conductivity, $e$ is the void ratio, $\sigma^{\prime}$ is the effective stress, $\gamma_{w}$ is the unit weight of water, $u$ is the excess pore water pressure, $z$ is the material coordinate, $G s$ is specific gravity, and $t$ is the time.

To solve the governing equation, void ratio-effective stress and hydraulic conductivity-void ratio constitutive relationships are required. These relationships are expressed as a power law function Eqs. (2) and (3), respectively:

$$
\begin{aligned}
& e=A \sigma^{\prime B} \\
& k=C e^{D}
\end{aligned}
$$

where, $A, B, C$ and $D$ are curved fitted constants.

Rearranging Eq. (1) with Eqs. (2) and (3), the governing equation becomes Eq. (4):

$$
\frac{d u}{d t}+\frac{\sigma^{\prime \beta}}{\alpha}\left(\frac{C e^{D}}{1+e}\right) \frac{\partial^{2} u}{d z^{2}}+\frac{\sigma^{\prime \beta}}{\alpha} \frac{\partial}{\partial z}\left(\frac{C e^{D}}{1+e}\right) \frac{\partial u}{d z}=\gamma_{b} \frac{d(\Delta Z)}{d t}(4)
$$

where, $\gamma_{b}=\gamma_{s}-\gamma_{w}, \alpha=A B \gamma_{w}$, and $\beta=1-B$.

An implicit finite difference method was selected to solve Eq. (4) due to numerical stability. Eq. (4) written in terms of differences is expressed as Eq. (5):

$$
\begin{gathered}
S_{i}^{j} \delta\left(K_{i}^{j}+D_{i}^{j}\right) u_{i+1}^{j+1}+\left(1-2 S_{i}^{j} K_{i}^{j} \delta\right) u_{i}^{j+1}+ \\
S_{i}^{j} \delta\left(K_{i}^{j}-D_{i}^{j}\right) u_{i-1}^{j+1}=u_{i}^{j}+\gamma_{b}(\Delta Z)
\end{gathered}
$$

where, $S_{i}{ }^{j}=\sigma_{i}^{\prime}{ }_{i}^{j \beta} / \alpha, K_{i}{ }^{j}=k_{i}^{j} /\left(1+e_{i}{ }^{j}\right), D_{i}{ }^{j}=1 / 4\left(k_{i+1}{ }^{j} /(1+\right.$ $\left.\left.e_{i+1}^{j}\right)-k_{i-1}^{j} /\left(1+e_{i-1}^{j}\right)\right), \delta=\Delta t /(\Delta z)^{2}, i$ is the material coordinate index, $j$ is the time index, $\Delta t$ is the time increment, and $\Delta z$ is the material coordinate increment.

The governing Eq. (5) can be solved by setting the initial condition and boundary condition. For a single drainage boundary condition, such as the standpipe test presented in this paper, Dirichlet boundary condition is used at the upper drainage boundary as zero excess pore water pressure; and Neumann boundary condition is applied as a no flow boundary at the base. 
Table 3 Finite strain consolidation model inputs.

\begin{tabular}{|c|c|c|c|c|c|c|c|}
\hline \multirow{2}{*}{ Tailings } & \multirow{2}{*}{$\begin{array}{l}\text { Initial solids } \\
\text { content (\%) }\end{array}$} & \multirow{2}{*}{ Initial height (m) } & \multirow{2}{*}{ Specific gravity } & \multicolumn{2}{|c|}{ Compressibility $(\mathrm{kPa})$} & \multicolumn{2}{|c|}{ Hydraulic conductivity $(\mathrm{m} / \mathrm{s})$} \\
\hline & & & & $A$ & $B$ & $C$ & $D$ \\
\hline Caustic & 22 & 1.0 & 2.48 & 3.12 & -0.219 & $2.00 \times 10^{-11}$ & 3.90 \\
\hline Non-caustic & 22 & 1.0 & 2.45 & 3.00 & -0.234 & $6.94 \times 10^{-11}$ & 3.70 \\
\hline
\end{tabular}

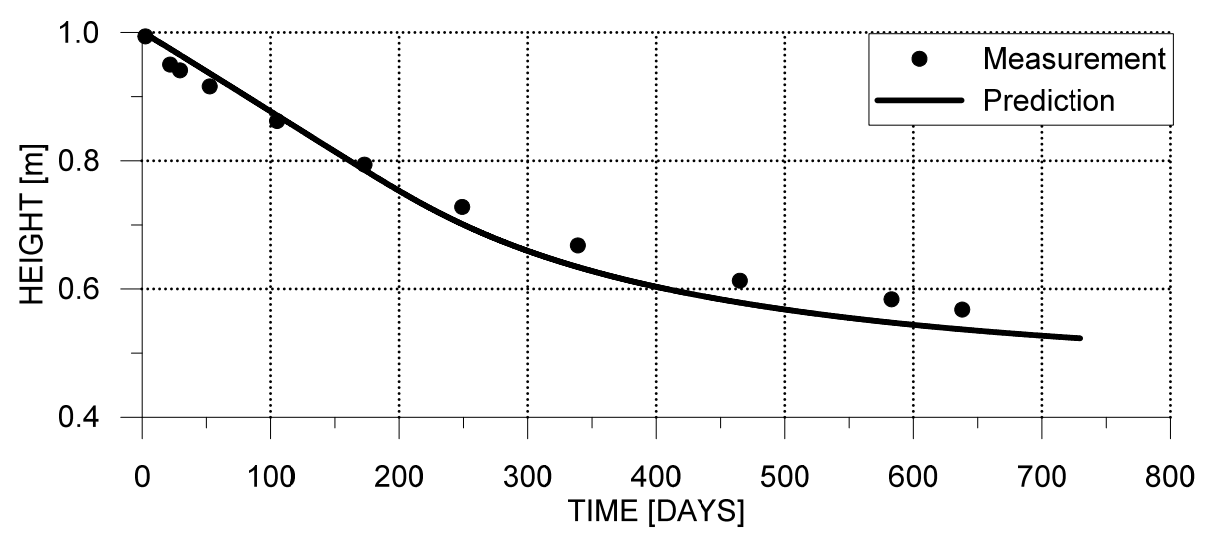

Fig. 9 Interface settlement comparison for caustic tailings.

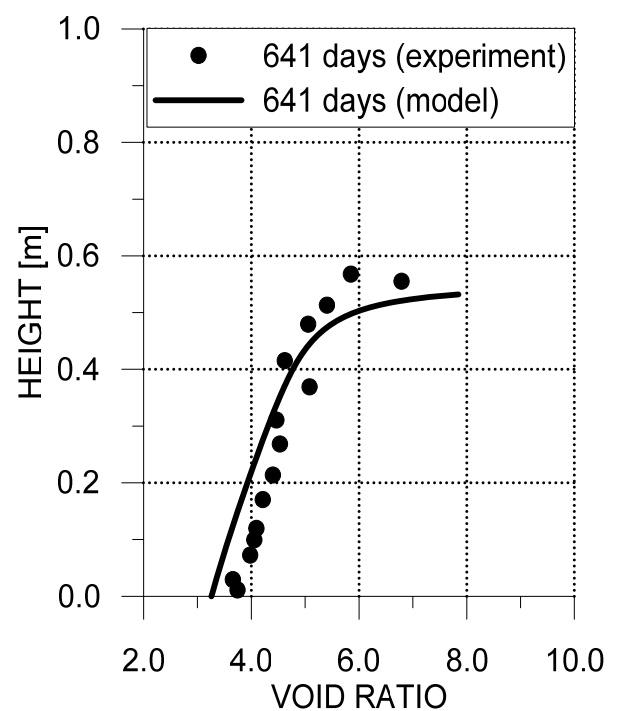

Fig. 10 Void ratio comparison for caustic tailings at the end of the test.

\section{Validation of the Finite Strain Consolidation Model}

The results from the standpipe tests including tailings-water interface height, pore water pressure profiles, and void ratio profiles were used to validate a finite strain consolidation numerical model. Table 3 summarizes the model input parameters for the validation. The validations for both tailings are presented in the following subsections.

\subsection{Caustic Oil Sands Tailings}

Figs. 9-11 show comparisons between the model predictions and the laboratory measurements for tailings-water interface settlement, void ratio and excess pore water pressure, respectively.

\subsection{Non-caustic Oil Sands Tailings}

Figs. 12-14 show tailings-water interface, excess pore water pressure and void ratio comparisons between the model and the laboratory measurement for the non-caustic oil sands tailings.

It can be observed in Fig. 9 that the interface settlement can be accurately predicted by the model for the caustic fine tailings while there is a slight discrepancy for interface settlement prediction for the non-caustic oil sands tailings (Fig. 12). The non-caustic tailings appear to initially consolidate more rapidly than the model with the selected relationships would predict. By applying Pane and Schiffman's approach to calculate hydraulic conductivity [11] from the standpipe result, an initial hydraulic conductivity for the non-caustic oil sands tailings was re-plotted in Fig. 15. It is found that the material in the standpipe has a slightly greater initial hydraulic conductivity than was originally estimated in the slurry consolidometer 
and used in the selected relationship.

The excess pore water pressure comparison for the caustic fine tailings show a generally good agreement with the experimental data for the caustic tailings (Fig. 11). Under-estimation of the excess pore water pressure dissipation however is found for the non-caustic case (Fig. 13). Similarly to the interface prediction, the apparently higher hydraulic
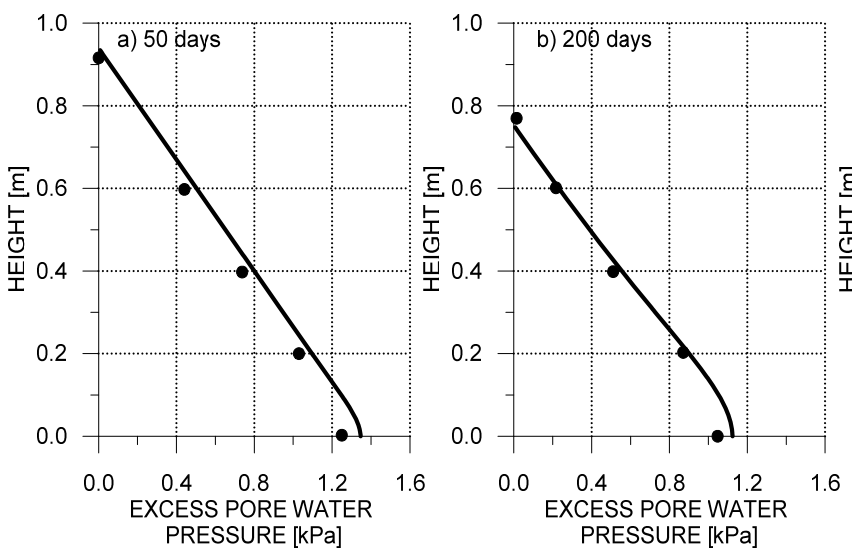

conductivity in the standpipe will also cause the dissipation to be slightly faster.

Figs. 10 and 14 show that the final void ratio profiles for both tailings can be adequately captured by the model.

Regardless of the small discrepancies observed in this verification, in a practical sense, the model is considered consistent with the standpipe data for both
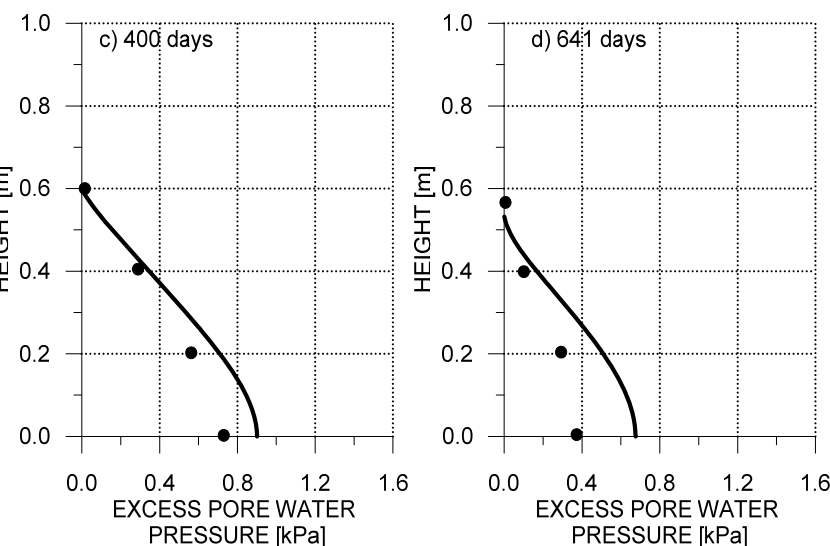

Fig. 11 Excess pore water pressure comparisons for caustic tailings.

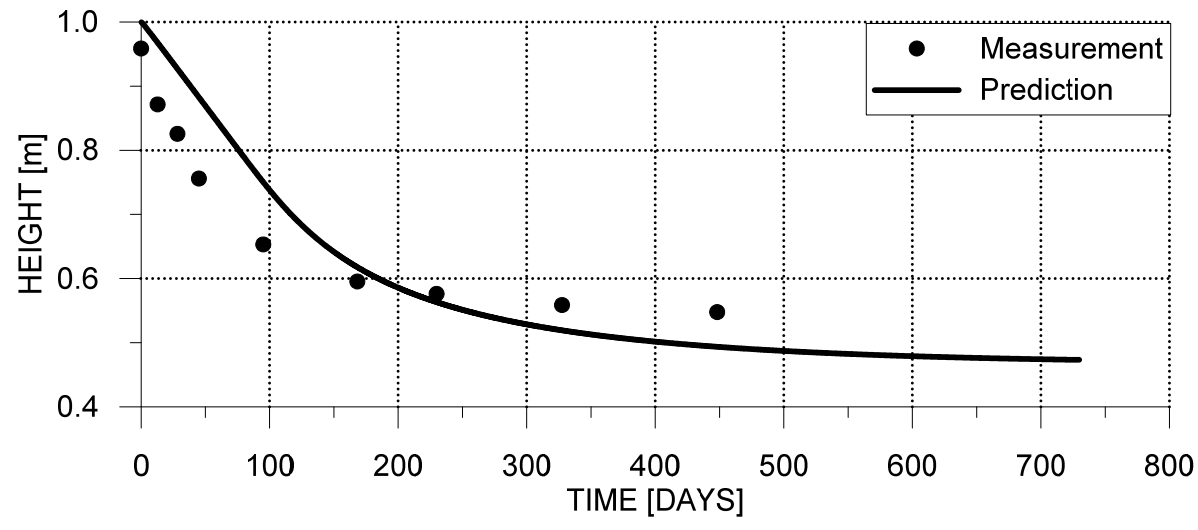

Fig. 12 Interface settlement comparison for non-caustic tailings.
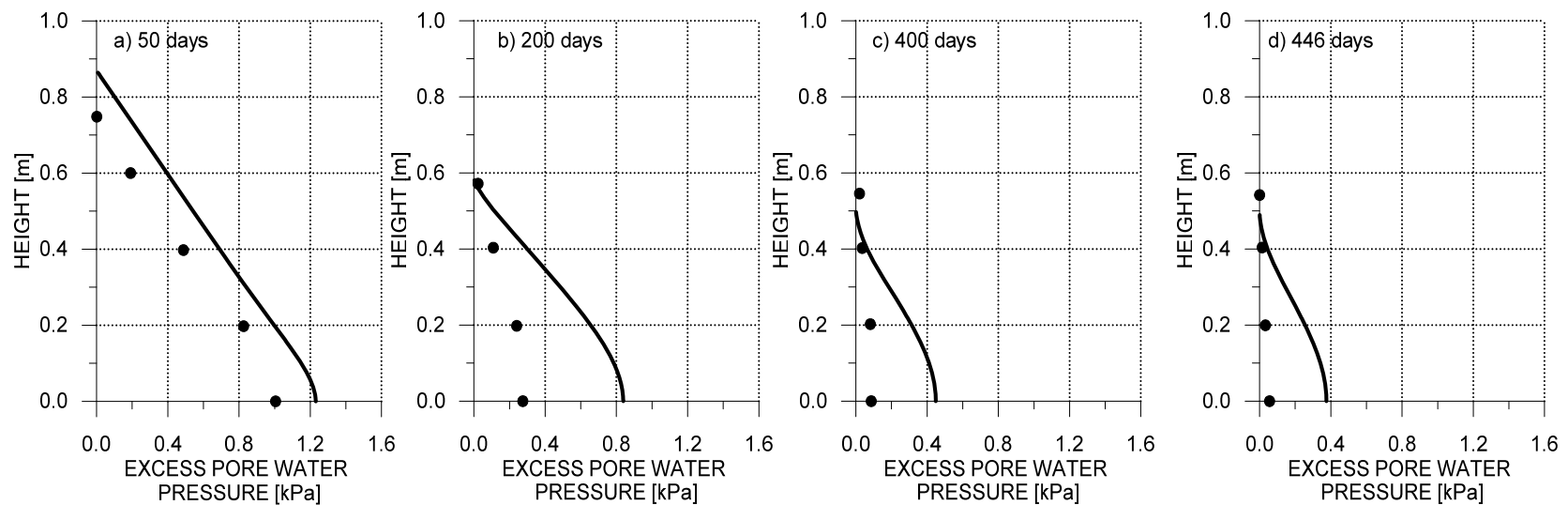

Fig. 13 Excess pore water pressure comparison for non-caustic tailings. 


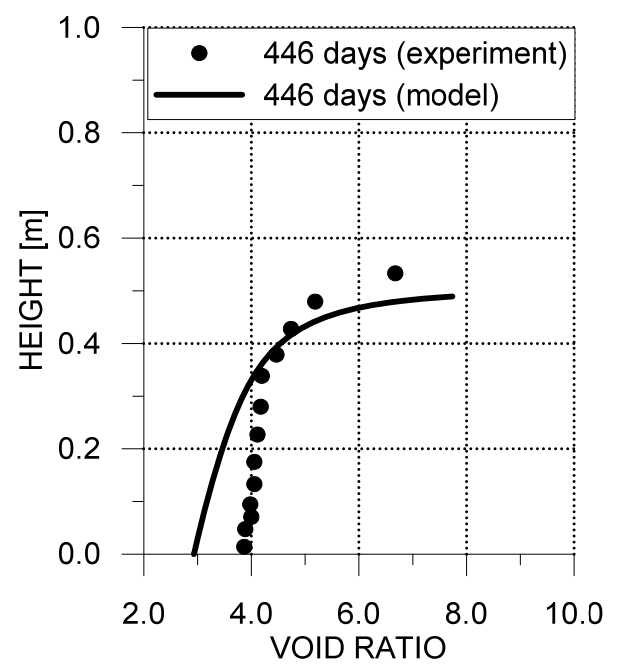

Fig. 14 Void ratio comparison for non-caustic tailings at the end of the test.

tailings materials. This model will be used to assess volume change implication in commercial scale tailings ponds in the next section.

\section{Modeling Commercial Scale Tailings Ponds}

The commercial tailings ponds in the open pit oil sands mining operations have various shapes and sizes depending on site-specific mining strategy. Though commonly found are a tailings pond covering a large and flat area. For instance, Syncrude West In-Pit covers an area of approximately $2.5 \mathrm{~km} \times 3.5 \mathrm{~km}$ and contains tailings of about $40 \mathrm{~m}$ deep; Shell Muskeg
River Mine External Tailings Facility has a footprint of approximately $3 \mathrm{~km} \times 4 \mathrm{~km}$ and contains tailings of up to $50 \mathrm{~m}$; and CNRL (Canadian Natural Resources Limited) Horizon External Tailings Facility stores tailings of about $20 \mathrm{~m}$ deep and covers an area of about $3 \mathrm{~km} \times 7 \mathrm{~km}$ [12]. These tailings ponds are either in-pit or out-of-pit ponds. The in-pit tailings pond is where the mining is complete and the area is available for tailings storage. The development of the in-pit containment can take from 5 to 10 years [13]. The out-of-pit tailings pond is where tailings is stored in the out-of-pit above ground facility while the in-pit storage is being developed. Due to the large tailings volume and extremely slow natural dewatering behavior of the tailings, these tailings pond are large.

To demonstrate differences between caustic and non-caustic oil sands tailings consolidation performance and their potential impacts on the tailings storage requirement, a hypothetical commercial scale tailings pond with a tailings discharge rate of rise of about 3 $\mathrm{m} / \mathrm{year}$, and a filling period of 20 years was selected for a commercial scale modeling analysis. The pond is assumed to have one way drainage (upward flow). Fig. 16 shows predicted tailings-water interface height with time. Fig. 17 shows the predicted rate of water release.



Fig. 15 Hydraulic conductivity of fine tailings. 


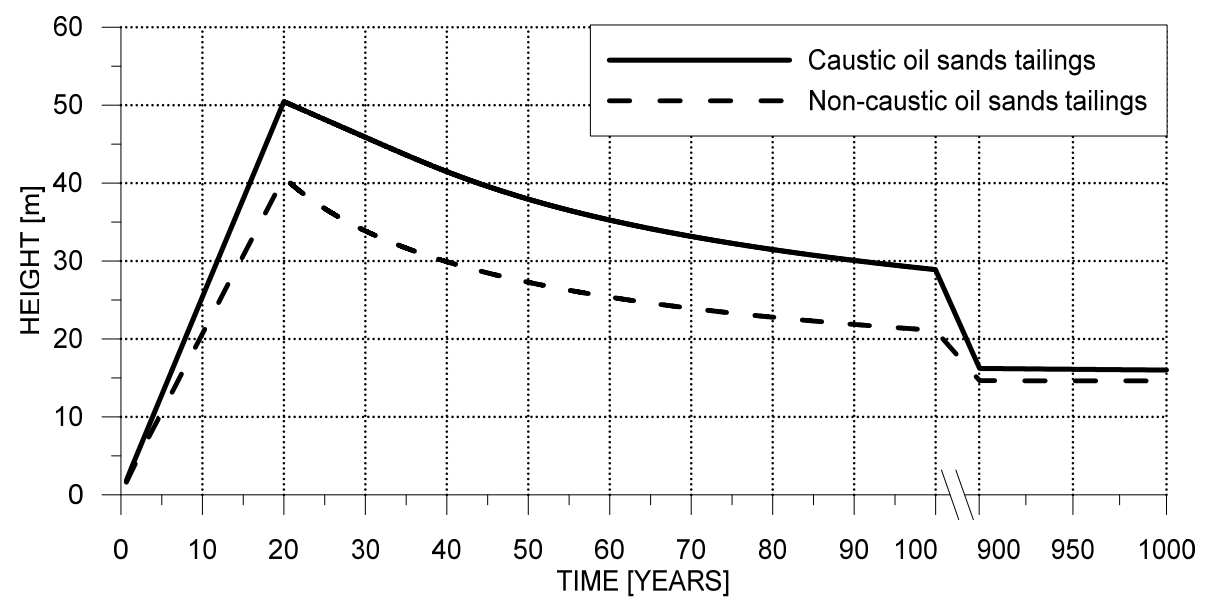

Fig. 16 Hypothetical commercial scale pond simulation - tailings-water interface prediction.

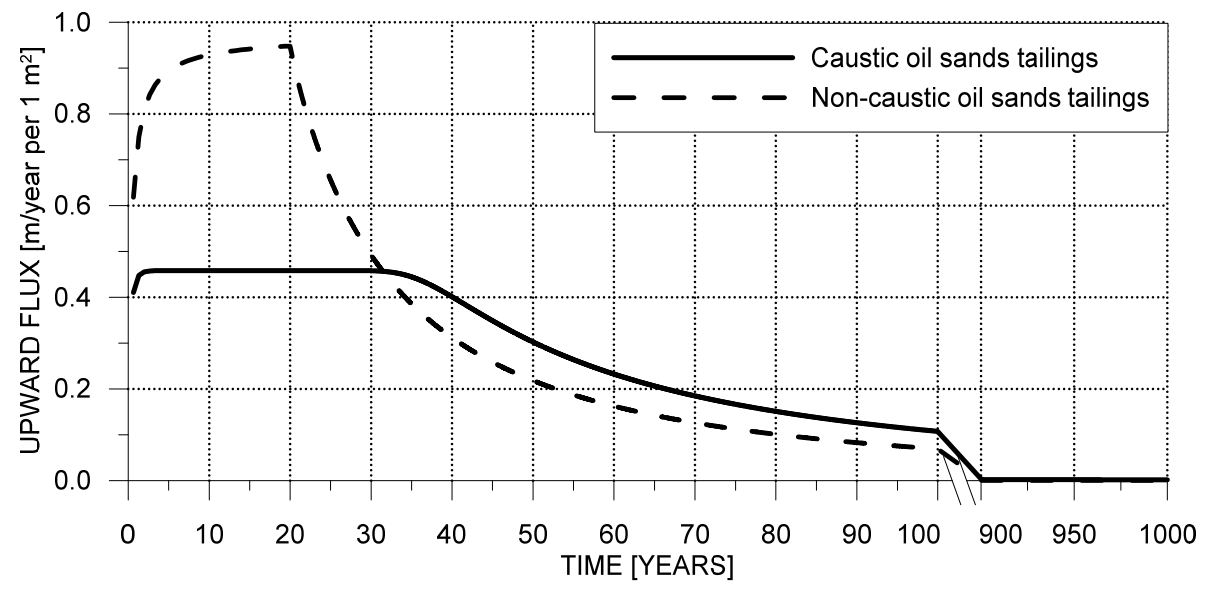

Fig. 17 Hypothetical commercial scale pond simulation - rate of water release prediction.

The model results indicate that the non-caustic oil sands tailings with its potential greater hydraulic conductivity would consolidate at a much higher rate compared to that of the conventional caustic tailings. The non-caustic oil sands tailings would approximately double the initial water release flux (Fig. 17), and increase containment capacity up to $20 \%$ (Fig. 16). As a result, the use of the non-caustic extraction process could increase the rate of water recycling, reduce make-up water from the Athabasca River and reduce the amount of the earthwork dyke volume necessary for the containment.

It is also found that, as expected due to the similarity in the compressibility of both tailings, the ultimate predicted tailings volumes are similar for both tailings at the end of self-weight consolidation. Full consolidation would take several centuries.

\section{Discussion and Conclusions}

In this paper, the results of the $1 \mathrm{~m}$ standpipe tests on caustic and non-caustic oil sands tailings were presented. Due to the less dispersive extraction method, the non-caustic tailings was found to consolidate at a much greater rate compared to that of the caustic case.

Large strain consolidation tests were performed to obtain tailings compressibility and hydraulic conductivity relationships. The results show that the compressibilities of both tailings are similar, but the non-caustic tailings are more permeable than the caustic one. The compressibility and hydraulic conductivity relationships were then used to verify a finite strain consolidation model with the standpipe test data. Reasonably good agreements between the model and the standpipe data were obtained.

Finally, a commercial scale tailings pond was 
simulated to assess the impact of bitumen extraction methods on the large scale consolidation performance of the tailings. The results suggested that a significant increase on the rate of water recycling, less need for make-up water from the Athabasca River and a substantial decrease in the containment size may be obtained by using the non-caustic bitumen extraction process.

\section{Acknowledgments}

The authors would like to acknowledge the support from University of Alberta, Bright Beacon, Co., Ltd., Khon Kaen, Thailand and Advisian, Worley Parsons Group, Level 4, Signet House, 600 Murray Street, West Perth, Western Australia, Australia.

\section{References}

[1] Miller, W. G., Scott, J. D., and Sego, D. C. 2011. "Effect of Extraction Water Chemistry on the Self-weight Consolidation of Oil Sands Fine Tailings." Canadian Institute of Mining, Metallurgy and Petroleum Journal 2 (1): 40-54 .

[2] ASTM Standard D4221-99, 1999. 2005. Standard Test Method for Dispersive Characteristics of Clay Soil by Double Hydrometer, ASTM International, West Conshohocken, PA. DOI: 10.1520/D4221-99R05.

[3] ASTM Standard D422-63, 1963. 2007. Standard Test Method for Particle-Size Analysis of Soils, ASTM International, West Conshohocken, PA. DOI: 10.1520/D0422-63R07.

[4] Scott, J. D., Dusseault, M. B., and Carrier, W. D. 1985.
"Behavior of the Clay/Bitumen/Water Sludge System from Oil Sands Extraction Plants." Journal of Applied Clay Science 1 (12): 207-18.

[5] Miller, G. W. 2010. "Comparison of Geoenvironmental Properties of Caustic and Noncaustic Oil Sands Fine Tailings." PhD thesis, University of Alberta, Edmonton, $\mathrm{AB}$.

[6] Gibson, R. E., England, G. L., and Hussey, M. J. L. 1967. "The Theory of One-Dimensional Consolidation of Saturated Clays I Finite Non-linear Consolidation of Thin Homogeneous Layers." Géotechnique 17 (3): 261-73.

[7] Jeeravipoolvarn, S., Scott, J. D., Donahue, R., and Ozum, B. 2008. "Characterization of Oilsands Thickened Tailings." In Proceedings of the First International Oil Sands Tailings Conference, 132-42.

[8] Suthaker, N. N., and Scott, J. D. 1994. "Large Strain Consolidation of Oil Sand Fine Tails in a Wet Landscape." In Proceedings of the 47th Canadian Geotechnical Conference, 514-23.

[9] Scott, J. D., Kabwe, L. K., Wilson, G. W., Sorta, A., and Jeeravipoolvarn, S. 2013. "Properties Which Affect the Consolidation Behaviour of Mature Fine Tailings." In Proceedings of Tailings and Mine Waste 2013, 69-90.

[10] Somogyi, F. 1980. "Large Strain Consolidation of Fine Grained Slurries." Presented at the Canadian Society for Civil Engineering, Winnipeg, Manitoba.

[11] Pane, V., and Schiffman, R. L. 1997. "The Permeability of Clay Suspensions." Géotechnique 47 (2): 273-88.

[12] Amec Environment \& Infrastructure. 2013. Beach Fines Capture Study. Submitted to COSIA, June 2013, $466 \mathrm{p}$.

[13] Sobkowicz, J. C. 2011. "History and developments in the treatment of oil sands fine tailings." In Proceedings of the 14th International Conference on Tailings and Mine Waste, 11-30. 